\title{
Chemotherapy-Induced Nausea and \\ Vomiting \\ (CINV)
}

\author{
Dr. Mohammad A. Shazly, MD \\ Lecturer of Internal Medicine, \\ Department of Hematology and Bone Marrow transplantation, \\ Ain Shams University
}

\section{Introduction}

Traditionally, CINV has been the most-feared toxicity of chemotherapy for cancer patients. ${ }^{1}$ The magnitude is less than it was 30 years ago, but the problem still exists. Before modern antiemetics, highly emetogenic chemotherapy would cause vomiting on the first day of therapy in virtually all patients, and moderately emetogenic chemotherapy would cause vomiting in at least half of patients. For the more emetogenic agents, vomiting would persist into the delayed period in a significant number of patients. Delayed vomiting may even have affected more patients than acute vomiting.

Modern antiemetics have markedly decreased the incidence and severity of CINV. Vomiting has been decreased by as much as $80-90 \%$ for the most emetogenic chemotherapy. ${ }^{2}$ However, some vomiting is still present in a significant number of patients. At least $25-50 \%$ of patients still have at least some nausea and vomiting. ${ }^{3}$

\section{Risk factors for CINV}

The most important factor in determining if CINV will occur is the chemotherapy itself. Not all chemotherapies have the same propensity to induce nausea and vomiting (Table 1). Highly emetogenic agents, such as cisplatin, would induce vomiting in virtually all patients if no antiemetics were given. However, other chemotherapeutic agents are associated with minimal or no CINV. It is important to understand the level of risk for the chemotherapeutic regimen that is being used to design an antiemetic regimen that matches the emetogenicity of the chemotherapy itself.

There are patient characteristics that modulate the emetic response. Knowing these characteristics enables us to understand which patients may require extra attention to obtain good control of nausea and vomiting. Younger patients are more likely to vomit than 
older patients, given the same chemotherapy. ${ }^{4}$ An inverse relationship exists between emetogenic potential and age (excluding newborns). More problems with nausea and vomiting will tend to occur with patients who are adolescents or in their 20s or 30s than with patients in their 60s, 70s, or $80 \mathrm{~s}$. We need to be more vigilant and perhaps more aggressive in our antiemetic management of younger patients. Given the same chemotherapy, women will vomit more than men. ${ }^{5,6}$ The reason for this difference is unknown, but it has been consistently found.

Therefore, for example, CINV would be more likely among breast cancer patients, who tend to be younger women, than among patients with head and neck cancer, who are often older men. Patients with a history of heavy alcohol use are less likely to have nausea and vomiting with chemotherapy. ${ }^{7,8}$

The mechanism of this phenomenon is unknown, although it is unlikely to be a direct effect of alcohol or chronic exposure to alcohol. Alcohol itself does not induce protection from vomiting, and acute intoxication would not help the patient. However, a tendency toward alcoholism may reflect important differences in neurotransmitter receptor pathways between different patients.

Table (1): Emetic Risk of Common Chemotherapy Agents.

\begin{tabular}{|c|c|}
\hline $\begin{array}{l}\text { High Risk } \\
>90 \% \text { of patients }\end{array}$ & $\begin{array}{ll}\text { - } & \text { Cisplatin } \\
\text { - } & \text { Dacarbazine } \\
\text { - } & \text { Nitrogen mustard } \\
\text { - } & \text { Cyclophosphamide/Doxorubicin }\end{array}$ \\
\hline $\begin{array}{l}\text { Moderate Risk } \\
>30 \% \text { of patients }\end{array}$ & $\begin{array}{ll}\text { - } & \text { Doxorubicin } \\
\text { - } & \text { Carboplatin } \\
\text { - } & \text { Cyclophosphamide }\end{array}$ \\
\hline $\begin{array}{l}\text { Low Risk } \\
>10 \% \text { of patients }\end{array}$ & $\begin{array}{ll}\text { - } & \text { Paclitaxel } \\
\text { - } & \text { Etoposide }\end{array}$ \\
\hline $\begin{array}{l}\text { Minimal Risk } \\
<10 \% \text { of patients }\end{array}$ & $\begin{array}{ll}\text { - } & \text { Chlorambucil } \\
\text { - } & \text { Vinorelbine }\end{array}$ \\
\hline
\end{tabular}

\section{Types of CINV: Acute, Delayed, Anticipatory and Refractory}

CINV tends to be divided into different categories, with the 2 main ones being acute and delayed nausea and vomiting. Acute nausea and vomiting occurs within the first 24 hours after chemotherapy. Delayed nausea and vomiting occurs after that first 24 hours, from 24 to 120 hours. The dividing line between the 2 categories is a line of convenience and not an exact dividing line. Delayed nausea and vomiting can begin as early as 16 hours 
after chemotherapy is administered. Acute nausea and vomiting tends to appear 2-6 hours after the most emetogenic chemotherapies are administered.

Delayed nausea and vomiting is more common with chemotherapies classified as high-moderate or highly emetogenic. The use of antiemetic is usually not required in patients receiving minimal or low emetogenic chemotherapy.

Because acute vomiting and delayed vomiting have different remedies, they must be distinguished. They both involve multiple neurotransmitter and neurotransmitter receptor pathways, the serotonin pathways, the neurokinin pathways, steroid-related pathways, and dopaminergic pathways. However, the relative contribution of different pathways to different phases of nausea and vomiting may change. For example, during the acute period, the serotonergic pathways tend to be the key pathways, and the neurokinin pathways have a lesser role. During later periods, neurokinin pathways have a greater role, and serotonin pathways tend to have a lesser role.

Anticipatory vomiting is a very different but related phenomenon. Whereas acute vomiting and delayed vomiting result from the direct chemical effects of chemotherapies on the body, anticipatory vomiting is a learned response. When a person has a bad experience with chemotherapy, then the thought of chemotherapy, the sight of the hospital, or any reminder may activate this learned response. In essence, it is an almost Pavlovian reflex in which a nonphysical stimulus will lead to a certain predictable response. Anticipatory vomiting is misnamed, as it is a learned response that could occur at any time before, during, or after chemotherapy. If a patient who had a previous bad response to chemotherapy receives a second cycle of chemotherapy and has persistent nausea and vomiting that is not responding to standard emetic agents, one must consider that a learned response might be part of that reaction.

Agents such as benzodiazepines are effective against learned responses. When a learned response has taken hold, it may be best to add a benzodiazepine rather than another antidopaminergic, antiserotonergic, or NK-1-blocking agent. The best way to prevent a learned response is not to learn it at all. In any area of supportive care, prevention is much more effective than treatment.

Nausea and vomiting are considered breakthrough or refractory when they have not responded to standard antiemetic agents. A learned response should be considered as an additional factor. Other causes of nausea and vomiting rather than the chemotherapy should also be considered. A patient receiving chemotherapy can still experience nausea and vomiting unrelated to treatment from causes such as bowel obstruction, brain 
metastases, gastroenteritis, or electrolyte abnormalities, all of which would need to be addressed in different ways.

Patients with refractory CINV might benefit from rotation of antiemetics. The best rotation strategy is to move to a family of antiemetic agents that have not been tried previously. For example, if a patient had already received an antiserotonergic agent, a corticosteroid, and an NK-1-blocking agent, then an antidopaminergic agent might be given to see if it would be more effective. ${ }^{9}$

\section{Mechanisms of chemotherapy-induced nausea and vomiting and antiemetic agents}

The emesis reflex has evolved to defend against ingested toxins, and it is widespread in the animal kingdom. ${ }^{10}$ Since chemotherapeutic agents are toxins, emesis is a common side effect of anticancer therapies; nausea and vomiting are especially pronounced with DNA alkylating agents, such as cyclophosphamide, cisplatin, and carmustine.

The emetic response has several key stages. ${ }^{11}$ In the first stage, chemotherapy administration damages enterochromaffin cells in the gastrointestinal (GI) tract, causing a release of serotonin. The serotonin then binds to 5 -hydroxytryptamine- 3 (5-HT3) receptors on the vagal afferents, triggering sensory inputs that project from the GI tract to the emetic center in the brain stem. The area postrema in the chemoreceptor trigger zone (CTZ) is also activated by the vagal afferents. Chemoreceptors in the area postrema are found outside the blood-brain barrier, and can also be directly activated by the blood-borne chemotherapeutic agents. These receptors are activated by several transmitters, including serotonin, dopamine, and substance $P(S P)$. The final stage of emetic activation occurs at the emetic center. Importantly, the emetic center is not an anatomically distinct center, but rather a network of loosely organized neurons throughout the medulla oblongata that is activated sequentially during emesis. ${ }^{12}$ The emetic center receives signals through afferents from the $\mathrm{Gl}$ tract, higher cortical centers, vestibular centers, and the area postrema (figure1). Consolidation of these signals at the emetic center and a subsequent output through vagal efferents to the abdominal muscles, diaphragm, and stomach results in the emetic response. The emetic response involves several transmitters, 3 of which have been the focus of drug development: dopamine, serotonin, and substance $\mathrm{P}(\mathrm{SP})$. 


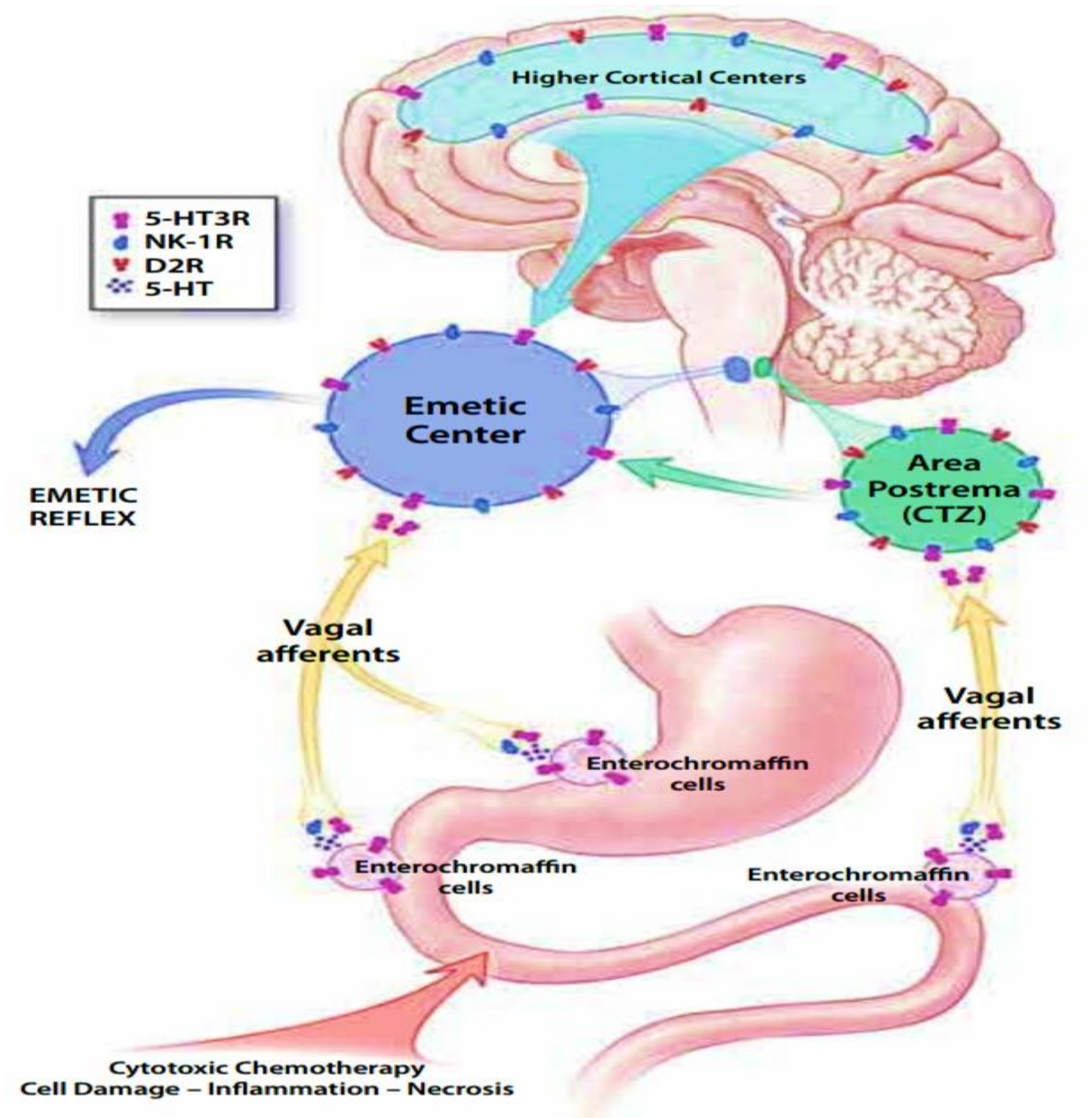

Figure (1): Activation of the emetic response by chemotherapy. ${ }^{5}$

The gastrointestinal tract can be damaged by cytotoxic chemotherapy, triggering the release of serotonin from enterochromaffin cells that then initiates a sensory input through abdominal vagal afferents. Chemoreceptors in the area postrema are also activated by different transmitters, including serotonin, dopamine, and substance P. Signal consolidation occurs at the dorsal vagal complex composed of the emetic center, area postrema, and vagal afferent terminals. Signaling output through vagal efferents to the abdominal muscles, diaphragm, and stomach results in the emetic response. CTZ=chemoreceptor trigger zone; 5HT3=5-hydroxytryptamine-3 receptor; NK-1R=neurokinin-1 receptor.

\section{Treatment of CINV}

Since the 1990s, CINV treatment has included the use of corticosteroids. The most commonly used corticosteroid has been dexamethasone. Dexamethasone acts through multiple mechanisms that are not well understood. ${ }^{10}$ One hypothesis suggests that it may increase the low 
cortisol levels associated with nausea and vomiting. Additionally, corticosteroids are known to be anti-inflammatory, since they block prostaglandins and release endorphins, which can make patients feel better. Corticosteroids are still part of current CINV therapy ${ }^{13}$; they are not typically used by themselves, but their efficacy is additive when they are combined with other antiemetics. $^{10}$

Early treatments of CINV also used dopamine D2 receptor antagonists, with metoclopramide being the most common. ${ }^{14}$ Metoclopramide is thought to act on the periphery, the CTZ, and the emetic center. ${ }^{15}$ Also, metoclopramide is a weak 5-HT3 receptor antagonist, ${ }^{16}$ which has led to some postulation that this activity may account for some of antiemetic effects seen with metoclopramide.

\section{Newer Treatment of CINV}

A breakthrough in the management of CINV occurred in 1991, when ondansetron came to the market. Ondansetron is a 5-HT3 receptor antagonist that prevents the stimulation of vagal afferents by serotonin released from enterochromaffin cells and the subsequent signaling to the emetic center in the brain stem. ${ }^{17}$ The chemical structure of ondansetron resembles the structure of serotonin. Several other 5-HT3 receptor antagonists were introduced to the market throughout the 1990s, including granisetron, tropisetron, and dolasetron. These agents all have structures that are similar to serotonin, and they work by binding to the serotonin side of the 5-HT3 receptor, blocking its actions on the vagal afferents. The use of ondansetron and other first generation antagonists constituted a major advancement in the treatment of acute CINV. NK-1 receptor antagonists were the next class of drugs that came on the market for CINV treatment. ${ }^{18}$

Aprepitant was approved in 2003, and was also a significant advance in the treatment of CINV. NK-1 receptor antagonists are thought to work in higher cortical centers and in the dorsal vagal complex in the brain stem. Brain penetration is essential to the activity of NK-1 antagonists, ${ }^{19}$ as their primary site of action is thought to be mediated centrally rather than at the level of the gut. In contrast to the first-generation 5-HT3 receptor antagonists, NK-1 receptor antagonists work to prevent both acute and delayed emesis. Besides aprepitant, 2 other NK-1 receptor antagonists are currently in clinical development: netupitant and rolapitant. These agents are in late-stage clinical trials, so they may be available in the next few years.

\section{The Unique Pharmacology and Clinical Profile of Palonosetron}

Palonosetron is a second-generation 5-HT3 receptor antagonist with a unique pharmacology that has been consistently superior at preventing delayed emesis compared to 
other 5-HT3 receptor antagonists. ${ }^{20}$ Palonosetron is the only 5-HT3 receptor antagonist that is labeled for both acute and delayed emesis; the other 5-HT3 receptor antagonists are labeled only for acute emesis. Palonosetron exhibits a higher binding affinity and a longer plasma half-life than other agents in its class. The binding of palonosetron is 30 -fold and 100 -fold more potent than granisetron and ondansetron, respectively. ${ }^{21}$ Further, palonosetron has a plasma half-life of approximately 40 hours; the half-life of granisetron and ondansetron is 5 -fold to 10 -fold shorter. ${ }^{22}$ However, differences in binding affinity and plasma half-life do not explain palonosetron's unique ness in the clinic. If its effects on delayed emesis were due to palonosetron being a more potent compound, giving more of the weaker drug would have the same effect. Similarly, if its efficacy were the result of longer half-life alone, a drug with a shorter half-life that was administered more frequently would be equally efficacious. However, ondansetron could not mimic palonosetron's efficacy when given at higher doses and beyond 24 hours after chemotherapy. ${ }^{23}$

Binding of palonosetron exhibited positive cooperativity, meaning that when one palonosetron molecule binds, it increases the affinity of the receptor for a second palonosetron molecule. These traits were unique to palonosetron and were not seen with ondansetron or granisetron, which exhibited simple bimolecular binding. ${ }^{24}$ Additional comparison studies indicated that the $5-\mathrm{HT} 3$ receptor could be internalized into the cell by palonosetron but not by ondansetron or granisetron. ${ }^{25}$ When palonosetron binds, it downregulates and internalizes the 5-HT3 receptor, resulting in persistent long-term inhibition of receptor function. One surprise finding was that palonosetron could also suppress NK-1 receptor function. ${ }^{26}$ Research focused on NK-1 receptors because they are associated with delayed emesis. Since palonosetron helps prevent delayed emesis, it was thought to possibly have activity at the NK-1 receptor. However, palonosetron does not bind to the NK-1 receptor. ${ }^{23}$ Evidence of crosstalk between the NK-1 receptor and the 5-HT3 receptor was published in the early 2000 s, showing that activity at the 5 -HT3 receptor could influence the NK-1 receptor function and vice versa. ${ }^{27}$

Given the efficacy of palonosetron on delayed emesis and its ability to internalize the 5-HT3 receptor, the question that emerged was whether palonosetron could indirectly block the NK-1 signaling pathway. Rats were used to test if palonosetron, ondansetron, or granisetron could block NK-1 receptor responses in nodose ganglia, the ganglia associated with the vagal afferents discussed above. The rats were given cisplatin, and 10 hours later, the neuronal response to SP was measured. The rats were then given an intravenous dose of ondansetron, granisetron, or palonosetron. The antagonists were allowed to wash away, and the neuronal response to SP was measured again. ${ }^{27}$ Palonosetron, but not ondansetron or 
granisetron, inhibited the NK-1 agonist response as measured through SP. The results showed that exposure to palonosetron inhibited the NK-1 agonist response in vivo.

More recent studies showed that when palonosetron and an NK-1 receptor antagonist were administered together, they could inhibit the SP response with a synergistic effect. ${ }^{9}$

\section{References}

1. Coates A, Abraham S, Kaye SB, et al. On the receiving end-patient perception of the side-effects of cancer chemotherapy. Eur J Cancer Clin Oncol. 1983; 19:203-208.

2. Gralla RJ, Itri LM, Pisko SE, et al. Antiemetic efficacy of high-dose metoclopramide: randomized trials with placebo and prochlorperazine in patients with chemotherapy-induced nausea and vomiting. N Engl J Med. $1981 ; 305: 905-909$.

3. Grunberg SM, Deuson RR, Mavros P, et al. Incidence of chemotherapy-induced nausea and emesis after modern antiemetics. Cancer. 2004; 100:2261-2268.

4. Booth CM, Clemons M, Dranitsaris G, et al. Chemotherapy-induced nausea and vomiting in breast cancer patients: a prospective observational study. J Support Oncol. 2007; 5:374-380.

5. Pollera CF, Giannarelli D. Prognostic factors influencing cisplatin-induced emesis. Definition and validation of a predictive logistic model. Cancer. 1989; 64:1117-1122.

6. Osoba D, Zee B, Pater J, Warr D, Latreille J, Kaizer L. Determinants of postchemotherapy nausea and vomiting in patients with cancer. Quality of Life and Symptom Control Committees of the National Cancer Institute of Canada Clinical Trials Group. J Clin Oncol. 1997; 15:116-123.

7. Hassan BA, Yusoff ZB. Genetic polymorphisms in the three malaysian races effect granisetron clinical antiemetic actions in breast cancer patients receiving chemotherapy. Asian Pac J Cancer Prev. 2011; 12:185191.

8. Kim KI, Lee DE, Cho I, et al. Effectiveness of palonosetron versus other serotonin 5-HT3 receptor antagonists in triple antiemetic regimens during multiday highly emetogenic chemotherapy. Ann Pharmacother. 2012;46:1637-1644.

9. Grunberg SM. Overview of Chemotherapy-Induced Nausea and Vomiting.Clinical Advances in Hematology \& Oncology.2013;11:9-10

10. Rudd JA, Andrews PLR. Mechanisms of acute, delayed, and anticipatory emesis induced by anticancer therapies. In: Hesketh PJ, ed. Management of Nausea and Vomiting in Cancer and Cancer Treatment. Sudbury, MA: Jones and Bartlett Publishers; 2005.

11. Wang SC, Borison HL. The vomiting center; a critical experimental analysis. Arch Neurol Psychiatry. 1950;63:928-941.

12. Hornby PJ. Central neurocircuitry associated with emesis. Am J Med. 2001; 111(suppl 8A):106-112.

13. Basch E, Prestrud AA, Hesketh PJ, et al. Antiemetics: American Society of Clinical Oncology clinical practice guideline update. J Clin Oncol. 2011;29:4189-4198. 
14. Gralla RJ. Metoclopramide. A review of antiemetic trials. Drugs. 1983;25(suppl 1): 63-73.

15. Borison HL, Hawken MJ, Hubbard JI, Sirett NE. Unit activity from cat area postrema influenced by drugs. Brain Res. 1975;92:153-156.

16. Bianchi C, Beani L, Crema C. Effects of metoclopramide on isolated guinea-pig colon. 2. Interference with ganglionic stimulant drugs. Eur J Pharmacol. 1970; 12:332-341.

17. Cubeddu LX. Mechanisms by which cancer chemotherapeutic drugs induce emesis. Semin Oncol. 1992; 19:2-13.

18. Hesketh PJ, Grunberg SM, Gralla RJ, et al. The oral neurokinin-1 antagonist aprepitant for the prevention of chemotherapy-induced nausea and vomiting: a multinational, randomized, double-blind, placebocontrolled trial in patients receiving high-dose cisplatin-the Aprepitant Protocol 052 Study Group. J Clin Oncol. 2003; 21:4112-4119.

19. Tattersall FD, Rycroft W, Francis B, et al. Tachykinin NK1 receptor antagonists act centrally to inhibit emesis induced by the chemotherapeutic agent cisplatin in ferrets. Neuropharmacology. 1996; 35:1121-1129.

20. Eisenberg P, Figueroa-Vadillo J, Zamora R, et al. Improved prevention of moderately emetogenic chemotherapy-induced nausea and vomiting with palonosetron, a pharmacologically novel 5-HT3 receptor antagonist: results of a phase III, single-dose trial versus dolasetron. Cancer. 2003; 98:2473-2482.

21. Wong EH, Clark R, Leung E, et al. The interaction of RS 25259-197, a potent and selective antagonist, with 5-HT3 receptors, in vitro. Br J Pharmacol. 1995;114:851 859.

22. Constenla M. 5-HT3 receptor antagonists for prevention of late acute-onset emesis. Ann Pharmacother. 2004; 38:1683-1691.

23. Geling O, Eichler HG. Should 5-hydroxytryptamine-3 receptor antagonists be administered beyond 24 hours after chemotherapy to prevent delayed emesis? Systematic re-evaluation of clinical evidence and drug cost implications. Journal of Clinical Oncology, 2005; 23(6): 1289-1294.

24. Rojas C, Stathis M, Thomas AG, et al. Palonosetron exhibits unique molecular interactions with the $5-\mathrm{HT} 3$ receptor. Anesth Analg 2008;107:469-478.

25. Rojas C, Thomas AG, Alt J, et al. Palonosetron triggers 5-HT(3) receptor internalization and causes prolonged inhibition of receptor function. Eur J Pharmacol. 2010;626:193-199.

26. Rojas C, Li Y, Zhang J, et al. The antiemetic 5-HT3 receptor antagonist Palonosetron inhibits substance Pmediated responses in vitro and in vivo. J Pharmacol Exp Ther. 2010; 335:362-368.

27. Minami M, Endo T, Yokota H, et al. Effects of CP-99, 994, a tachykinin NK(1) receptor antagonist, on abdominal afferent vagal activity in ferrets: evidence for involvement of $\mathrm{NK}(1)$ and $5-\mathrm{HT}(3)$ receptors. Eur $J$ Pharmacol. 2001; 428:215-220. 